\title{
The Experience of Information Distribution in a Distance Learning University: The Spanish Case
}

\author{
Carmen de Pablos \\ Rey Juan Carlos University, Madrid, Spain \\ cpablos@fcjs.uric.es
}

\author{
M. Juliana López \\ UNED University, Madrid, Spain
}

meguilaz@ind.uned.es

\begin{abstract}
Information and communication technologies offer us new possibilities to improve the way we develop our own work as both educators and researchers. In this paper we have stressed the particular case of their application to a Spanish Distance Learning University, the UNED, by emphasising the peculiarities of a distance learning traditional university, different from a virtual university or a traditional one that wants to use these technologies. First we offer a general vision about the University's main objectives, main procedures and traditional information systems used. Second we show the change of the situation when the University decided to implement new technological tools as Internet and the WebCT. We pay a special attention to how these tools are trying to solve the specific situations that a university with these special characteristics faces.
\end{abstract}

Keywords: distance learning, information and communication technologies, educational system, teaching style, learning style

\section{Introduction}

There are various proposed definitions for the concept of distance learning. However all of them contain a number of elements that are invariably repeated as a common item.

Of all the main characteristics, the most stressed ones are: the separation between professor and student, the use of technical tools, the organisation of support activities and tutorials, the flexible and independent way of learning, the bi-directional communication professor-student, and the use of computer procedures.

In this sense, Keegan (1980), a great supporter of distance learning practices, considers them as processes of teaching-learning composed by the following items: a) the physical separation professor-student and student-other students; b) the organisation of learning by an educational Institution; c) the use of technical tools for the didactic communication; d) the existence of bi-directional communication; e) and the possibility of establishing occasional professional meetings with didactic and socialised purposes.

In the same way, Hölmberg (1982) understands the process of didactic communication as a "guided conversation" characterised by the personal interaction produced between the professor and the student. Properly promoted it should provoke the motivation and the pleasure for learning. Well developed peda-

Material published as part of these proceedings, either on-line or in print, is copyrighted by Informing Science. Permission to make digital or paper copy of part or all of these works for personal or classroom use is granted without fee provided that the copies are not made or distributed for profit or commercial advantage AND that copies 1) bear this notic e in full and 2) give the full citation on the first page. It is permissible to abstract these works so long as credit is given. To copy in all other cases or to republish or to post on a server or to redistribute to lists requires specific permission from the publisher at Publisher@InformingScience.org gogical materials can positively help to these objectives.

The International Association for Distance Learning in 1974 established that "the distance learning system should be in conditions of solving the problem of the distance as a positive element for the deve lopment of the autonomy in learning." 
García Aretio (1996), by synthesising the existent definitions and by collecting some common features in all of them, proposed, as a working tool, the following definition "Distance learning is a technological system of bi-directional communication, that can be a massive one and that substitutes the personal interaction in the class between student and professor as a favourite way of learning throughout the systemic and joint action of various support resources and the help of an organisation and a tutorial, that will promote the independence and flexibility in the students way of learning”.

\section{History and Evolution of Distance Learning}

We can find the ancestors of distance learning in the first civilisations. The first data are found in the "instructive letters" that appear in the missives that are interchanged by bishops and church workers in the Sumerian and Egyptian civilisations. In the Roman civilisation we can also find some references to the Caesar, Ciceron and Horace writings and mainly in the Seneca's "moral Epistles". Other examples are the evangelical writings to the main followers and the letters of Bishops and clerical people from Rome to all of Christianity. In the Middle Ages Saint Agustin's interchange of letters with the Church Doctors and the letters between Luther and Melanchton are some good examples that illustrate how distance learning has always been practised.

However, learning by correspondence in a recognised way started in the eighteenth century with the development of the post and journals. One of the main consequences of the first Industrial Revolution was the use of mass communication, which made the information and the contact between professorstudent pos sible.

By the end of the nineteenth century in Europe and North America various models of distance learning, mainly based in the post contact, appeared. In 1905, the University of Chicago organised the first university department dedicated to distance learning.

In the sixties, various aspects influenced by the structure and methodology in this learning modality appear: on one hand, the technological computer and the micro electronic boom applied to the image and sound and, on the other hand, the economic development promoted the massive demand of educational goods and the need of a permanent education. The joint use of written material with other pedagogical instruments, such as the radio or the television, promoted the substitution of the term "by correspondence" for this other one "by distance".

\section{The University Distance Learning}

The massive implementation of distance learning in the university took place from the 60s to the 80s. The first countries to implement this educational system were Australia and the countries from East Europe, mainly the ancient URSS. The idea was to be able to train students without losing the production in their working centres. In 1969 the UK established the first distance learning university in Europe, the Open University.

However, not all the countries that have made a choice for this system of learning follow the same organisational and administrative model. It is clearly adapted to the particular socialcultural characteristics in each country. Two models have mainly been established.

On one hand is the most elemental model, with a production and distribution centre for the pedagogical materials, that executes a tutorial orientation by telephone, mail and computers. On the other hand is the mostly diffused model that shares main functions between a central organism and a group of centres of support. The central organism is in charge of the direction of the institution through the production of material, course programming, the co-ordination of learning aspects, and the expedition of titles and certificates. The mission of the support centres consists of orienting the student and assessing him in all the aspects; this is the model applied to the English Open University and to the Spanish one, the UNED. 


\section{The National Distance Learning University (UNED)}

The UNED was created by the Act 2310/72 the $18^{\text {th }}$ August, 1972. In this Act the main reasons for its creation and main characteristics of the educational model are stressed,

"The need to develop one of main basic principles of the educational reform, in the same opportunities for university access, obliges to make it possible the access to upper education to those that, by different reasons, residence, labour duties or any other can not attend the traditional university classes. From this perspective, the distance learning seems to be the most appropriate, the only one able to assure the required flexibility, without damaging the quality level of the learning style".

The UNED offers three different characteristics in comparison with main Spanish universities: 1) it is created to enable access to upper education for all the people that for space, temporal, physical or labour reasons can not attend a presence university; 2) the kind of model is the distance learning one that requires the same general conditions as the instruction systems, that it is to say, previous planing, process orientation, evaluation and feedback, but all of them subordinated to a specific methodology that has not been involved in space or time restrictions; 3 ) it comprises all the national territory which means a methodological renovation in the university learning.

It started in 1973 with the studies of Law, Philosophy and Literature and offered some special courses for the Direct Access to University for people over 25. A year later some other studies were incorporated.

Once it finished the first five years, the UNED started its external projection as one of the main policy aspects. This way the UNED formalised its integration in the European university environment.

Today the UNED offers sixteen different university studies including a Special Course for the incorporation into the University for people over 25 and some other programs: 6 masters degrees, 16 different titles as upper university specialist, 128 programs of teacher training, 85 programs of open learning and 5 summer courses.

\section{The UNED Objectives and Student Profile}

There are seven main objectives, explained in the Act of the UNED creation. All of them have to do with the promotion of distance learning practices to allow better possibilities to some student profiles It is logical to think that the student from the UNED university presents some particular characteristics that justify its reason for being. The UNED students constitute a heterogeneous group, with some common elements. García Aretio (1996) offers some of their characteristics: "distance learning students are normally of different ages, they have different qualifications and disperse residence, they search a way of independent learning, they work, they are mainly adults with little social interaction and partial dedication. They usually study at home or at work".

\section{Educational Model}

In 1998, The UNED defines its educatio nal model in the following terms,

"....it is based in the new learning theories under the experimental pedagogy, that considers the direct relationship professor-student it is not completely needed, since it is possible to learn in solitude certain scientific contents. A proper methodology that guaranties the clarity and quality of main contents and contains the technological ways to assure a fluid communication with the professor, is needed. To get this objective some pedagogical tools of a contrasted university quality are needed"

Table 1 shows the main differences between the presence and distance learning model. 


\begin{tabular}{ll}
\hline \multicolumn{1}{c}{ Presence } & \multicolumn{1}{c}{ Distance learning } \\
\hline Lack of function diversification & Multiple units and functions \\
Courses are simple made & Complex process of course production \\
Administrative problems in the timetables & Co-ordination problems \\
Many professors & Less professors \\
Few administrative staff & Lots of administrative staff \\
Lack of ties teacher-administrative staff & Lots of ties teacher-administrative staff \\
More elitist and selective & Greater democratisation in the access \\
Many courses with few students & Many students in each course \\
\hline
\end{tabular}

Table 1. Differences between presence and distance learning models (García Aretio, 1996)

\section{Organisational Model}

The UNED organisational model tries to join the needs of a Central Organism, in the administrative and academic level, with the needs of a decentralised student attention, by offering a large amount of didactic help. Its organisational structure is a bipolar one, since it comprises two kind of complementary organisms: The Central Part (or academic part) and the Associated Centres.

The Central Part is situated in a university campus in Madrid composed by teams of professors ascribed to various departments. It is the place where the main teaching guides, the subject programs, the didactic material and the evaluation criteria are developed. In the same way, the relationship with other professors for establishing common criteria is very important in the whole community in the Central Part.

The Associated Centres are distributed all around the national territory by extending their actions to the regional, local and even international environment.

There are 54 different Associated Centres, plus 4 institutional special centres, the centre in Equatorial Guinea and 9 support centres abroad.

The main functions in the Associated Centres are,

1. To offer academic support to the students by making the university closer to the places of residence.

2. To enable the tutorials that are taught in each centre, generally once a week in the afternoons.

3. To provide students with a number of well trained professors in case they have to solve difficulties in the process of learning.

4. To offer students some basic instrumental resources and proper materials.

5. To inform the new student by offering him or her the needed orientation to survive in the system.

6. To help as an element of information transmission with the Central.

7. To act as a focus of cultural diffusion in the university and other locations, especially in further places and other centres of upper education

8. To develop presence exams

9. To develop practices

10. To co-ordinate elections for student representations. 
In these centres some other support activities are developed, such as video-conferences, conferences, seminars and scientific meetings.

The professor-tutor has as these main functions (Botticario and Gaudioso, 2000):

- To orient students in their studies by following the pedagogical criteria and administrative guidelines coming from the departments

- To clear and explain student questions in relation to the main contents

- To participate in the continuous evaluation of students by making professors know about their preparation level

- To collaborate with the departments and represent them

- To develop research under the department direction.

The professors and tutor-professors tasks must be made in close contact with the departments they belong to, mainly for two motives: one so that the material and subject organisation is not affected by the evaluation of concrete situations in the students; second, so that main guides in the departments and teams can be transmitted with rigor.

\section{Tutorials}

Due to the special character of a non presence university, some considerations should be taken into account for the first day at class, by informing students about the following aspects:

- Main objectives of the present class

- Administrative data in relationship with the subject

- Objectives of the tutorial action

- Objectives of the subject

- General introduction

- Main structure for the subject and class planning

The UNED educational model is based in the co-ordination between the highly specific didactic material and the orientation techniques the professor develops in each centre.

In this sense, the relation between both is oriented on one hand to train the professor tutors in the distant teaching techniques and on the other hand to enable and accelerate the arrival of information to the students. These objectives are accomplished through:

a) Courses for professor-tutors programmed by IUED (University Institute for Distance Education)

b) Courses for tutors programmed by the department

c) Permanent contacts amongst professors in the Central and Associated Centres.

\section{Evaluation Systems}

\section{Distance evaluation system}

The evaluation system is composed of a group of evaluation practices that students must complete and send in by some deadline to the correspondent professor-tutor. The main advantages are: 1) A constant control in the student evolution is performed; 2) An obligation to create a planned schedule in the study; 3) They help to retain some fundamental aspects in the subject; 4) They offer questions that mean some 
re-elaboration in the acquired knowledge; 5) They allow a personal training for presence exams; 6) They orient the teaching team about different parts in the subject that introduce a higher difficulty for students.

\section{Presence exams}

These are some written tests developed in the Associated Centres, identical for all the students and referred to the different parts in the subject program.

The extraordinary exams in September are created for students to have a second chance of passing the exam. These exams are developed in the different Associated Centres and the professors constitute the Evaluation Council in charge of evaluations.

The students receive the exam results via mail.

\section{The tutor report}

The professor in the Central Part knows about the different student results through the report that the professor-tutor elaborates and sends to the Central Part before the presence exams. The weight of the report in the final mark is shown in the UNED Acts. The report reflects apart from main marks in the distance evaluation exams, some other evaluations about the students, such as interest in the subject, class participation, queries and participation in main activities organised in the Centre.

\section{Didactic Materials}

If they are important in all the educational systems, didactic materials are especially important in this one, since they constitute the main support material for students due to the fact that they do not have presence class. From this perspective, the distance education methodology is based in the following materials: a) didactic materials containing the knowledge they try to transmit; b) the communication channels that help as a link between professor and student and that allow the learning surveillance.

"Materials and communication channels are the distance educational means situated between the professor and the students to allow the transmission of knowledge in one direction and the evaluation of knowledge in the other" (Ramos, 1995). In this sense we have to take into account that the UNED educational model, given its special characteristics, needs special techniques. The use of a different methodology that takes into account the absence of synchronism and the spatial discontinuity between the sending and reception of the teaching message is needed.

The experience acquired from the first times has allowed the UNED to join a wide material for teaching purposes and it has shown a great efficacy in this learning model. According to their format, there are three kinds of materials: printing materials, audio-visual materials and multimedia materials.

All these materials must be used in a co-ordinated way in each subject, by allowing a joint programming.

In the main Act, article 85 the UNED defines that "the modality of distance learning means the implementation of a specific didactic methodology where communication systems and resources that include the use of printing, audio-visual means and new technologies are integrated".

\section{Printing Materials}

These are composed of all the printed didactic materials elaborated by the professor in a written way and that are needed for this educational model.

Amongst most important materials we can stress: the didactic units, the didactic guide, the additions, the exams for distance evaluation, the course guide and the program. 


\section{Didactic units}

These constitute the specific system of communication in the UNED. They must be the result of a planning that fixes the didactic objectives to be met. García (1997) defines them as "an integrated, organised and sequential group of basic elements that conform the process of teaching-learning with a sense, that allow the students, after their study to appreciate the result of their work".

The didactic unit must be a concrete guide, theme by theme, for the student focus by answering to the different moments of the learning effort that has to be done. It includes some techniques of study when dealing with some possible difficulties.

Normally the specific material in each subject is divided in 36 themes that are distributed in six didactic or thematic areas. The methodological schema in each subject is the following: a) summary, b) instructions for the study, c) content, b) bibliography, e) recommended activities, f) exercises for self-checking.

\section{Didactic guides}

These are brief manuals that help the student to structure and organise the information held in the base text, by enabling comprehension. It demands to plan the main themes, to signal key concepts, to indicate the exercises or activities and to anticipate the aspects of higher difficulty. The guide must be composed of:
a) a teacher's presentation
b) a general course introduction
c) the objective referred to the aims to be reached
d) the previous requirements where knowledge and skills are reflected
e) The basic materials and the complementary ones that are supposed to be needed
f) The course contents
g) The bibliographic orientations specified by didactic units

h) The orientation for the study, translated into suggestions on how to relate the different parts in the subject and how to integrate various sources of information

i) The activities to develop: obligatory and recommended ones

j) The glossary of main terms in the course

k) The evaluation criteria

\section{Additions}

These are publications that help to complement, modify or substitute the information that is included in the didactic units. They help to actualise each subject's program every period.

\section{Test of distance evaluation}

The student works on the materials at a distance and the tutor-professor corrects them. They are distributed via Associated Centres. They serve as didactic tools and as a way of self-evaluation since they help to the student study, they enable the psychological motivation and promote a tutorial orientation.

\section{Course guide}

The course guide is the reference framework for all the studies in the UNED. It shows the subjects that compose the studies in each group of studies, the specialities, and course descriptions. It includes didac- 
tic criteria for each subject. The main structure shows 1) general information about the UNED Educational model, 2) specific information about each faculty, 3) information about every subject.

\section{Subject program}

The program of the subject contains a detailed explanation of most important aspects in each theme including basic and complementary bibliography.

\section{Audio-visual Materials}

The UNED owns a Special Centre for Design and Production of Audio-visual materials (CEMAV) for the production of radio, video and audio programs. This is one of the compulsory services to develop a proper development in its model of distance education as it is shown in the Main Act 2310/1972 of its creation.

Audio-visual materials offer a variety of selection in formats, with specific possibilities that allow us to work on the didactic objectives in each subject. The different formats we are referring to are: audio, video-cassette, radio programs and TV programs.

\section{Radio}

The UNED owns a specific programme in Radio 3 from the National Radio in Spain for all the territory and of two hours of duration per day. They are dedicated to different subjects every day

The radio programs are divided into: a) programs for students in the different study programs (about 130.000 students), b) spaces dedicated to students in the programs for professor formation and open class (about 20.000 students); c) programs for students in the special course for university access for people over 25 years (about 25000 students); d) programs with a cultural character for the general public; e) informative programs where courses, seminars, research works are publicised.

All the Associated Centres provide a space with audio-visual tools for the students. There all the programs are recorded and the radio programs are included in the university web pages.

\section{Television}

In 1991 in collaboration with the National TV and the Madrid TV, the UNED took part in the program "to know". Nowadays in the national Spanish TV there is a weekly program "The adventure of knowing" where themes of open teaching are presented. Besides two days a week an informative program about the UNED is presented and themes included in the different specific subjects. In the classic channel in the Spanish television an hour daily is shown with programs referred to various studies in the UNED.

\section{Audiocassette}

This communication way offers the student the opportunity of not having a fixed timetable. It is composed by own productions.

\section{Video}

The main advantage of video comes from the possibility of putting together image and sound, by allowing experiences that are not easy to observe through other pedagogical materials.

\section{Communication Channels in the UNED}

The recent explosion of information and communication technologies has promoted the establishment of a different professor-student relation. Radio and television have just become ancient technologies to send sound and image. In the last years a rational application of new information and communication 
technologies has taken place throughout the educational system. These technologies are the result of applying computers and telecommunications to the educational landscape giving birth to what Cabanes (1993) has called "training engineering" as a combination of three main elements, materials, distribution channels and feedback systems amongst students and professors.

In the UNED educational system this application of information and communication applications is being used: advanced phone applications, video-text, video-conference and Internet.

\section{Advanced phone applications}

Some years ago a 24 hour service of automatic response, SIRA, was introduced. The student can freely access it to find information about the state of matriculation, application forms and marks obtained in different personal exams.

\section{Video-text}

In 1992, by using the Spanish net IBERTEX, video-text was introduced in the UNED as a system for communication. It was introduced as a system for public access with general information about the University, marks, pre-inscriptions, grants, courses and job offers. The information about different faculties was introduced as a restricted service access, only available under some restrictions (use of passwords).

\section{Video-conference}

The application of this tool in the UNED in 1993 enabled this University to be the first one in using ISDN for education. Today the Educational Network of Video-conferences in the UNED is composed of 38 teams.

A video-conference can be simultaneous conducted with more than one Associated Centre. With the modality of personalised video-conference, a more enriched relationship is developed between professor and student.

From the first application it has strongly been used as one of the main means to communicate in the UNED. Some video-conferences of a different nature have been developed, such as work meetings between professors in the Central Part and Associate Centres and tutors, conferences specialised in different themes of actuality, presentations, project discussions and even some distance exams have been developed.

\section{Internet}

The Internet is the most used multimedia support for the web documents. The UNED is connected via RedUUS network at the URL http://www.uned.es. It presents a portal where all general information about the university is shown, allowing the direct access to programs, professor, subjects, where profe ssors offer all the information they want to show to students or other professors, research groups.

The main characteristics of Internet, such as hypermedia, distributed, heterogeneous and collaborative system, make it a very good tool for the development of the following processes in the UNED:

- Courses in the net, didactic material are divulged.

- Students' tutorials. Email allows us to solve some student questions in a quick and easy way. With the distribution lists the content of main questions and answers are sent to all the subscribed students.

- Virtual Classes, by using distribution lists (Figure 1) or chats moderated forums can be established by professors, and they reproduce discussions in presence classes. The previous diffusion of materials adds an interactive element that makes the virtual class close to a real one. 


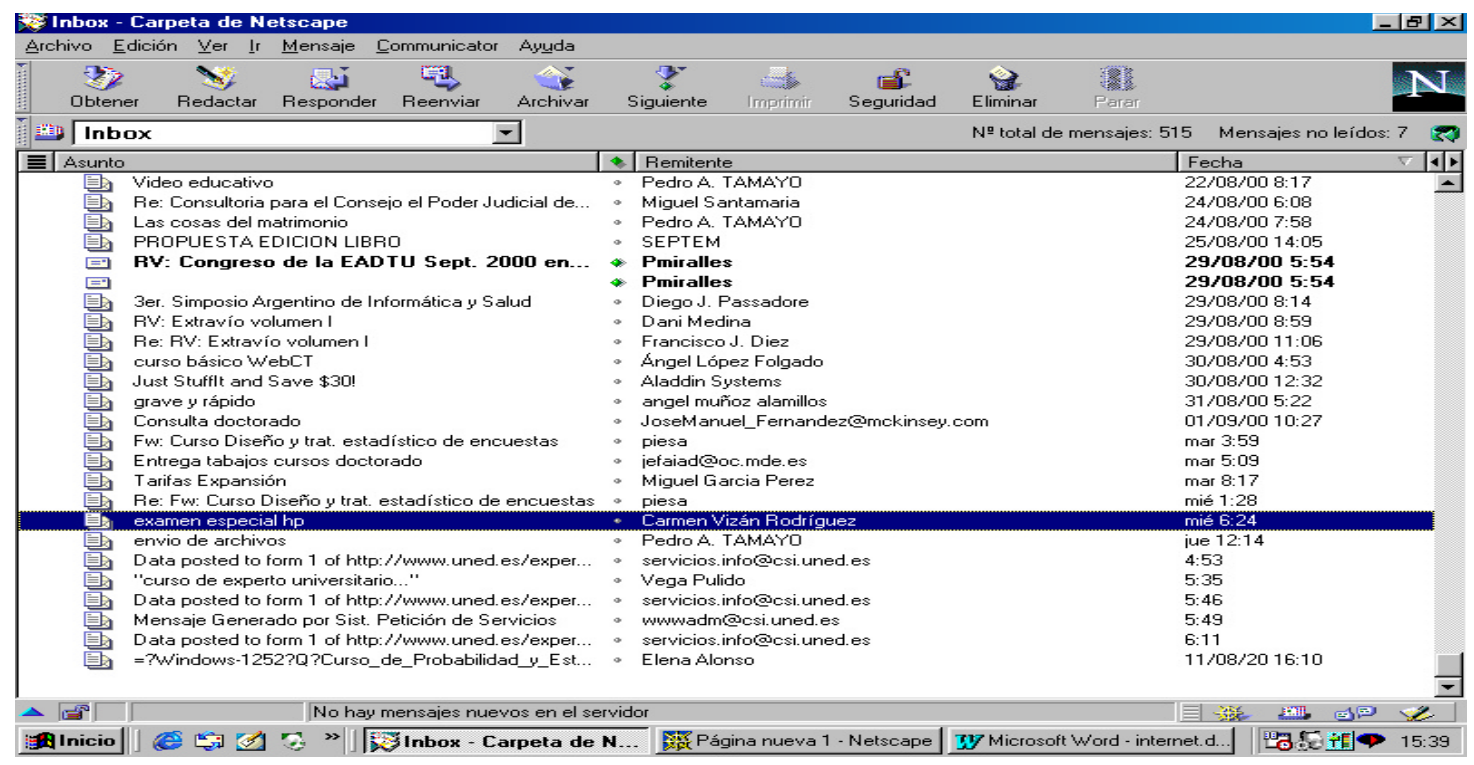

Figure 1. Distribution lists

- In the news the student can interchange documents with the rest of the class mates.

Figure 1 shows how the email in distance teaching is mainly oriented to tutorials, intercommunication student-professor and intercommunication amongst students.

\section{Web-based Project in the UNED}

The educational model of distance learning has changed in the last years with the new opportunities offered by new information and communication technologies.

In this project, started in 1997, the UNED has tried to establish a virtual community between students and professors with the main aim of acquiring knowledge by promoting the use of new technologies.

Since the main objective in the UNED is to base the teaching function in the student, this project tries to promote individualisation in making use of Internet services in the following way:

1. to enable an active way of learning

2. to offer additional means to learn

3. to develop a model of interaction and resources "on line" adapted to student s' needs

4. to promote ways of communication that enable the establishment of work groups amongst students and professors with same interests by increasing the flow of information amongst them

5. to stimulate the use of available resources

6. to combine the offer of alternative techniques in the teaching organisation by promoting student independence

7. to present the material by following the steps that improve the interaction in the ways of learning.

In order to get these objectives, an educational web must put together the following characteristics:

- a search service

- actualised documents

- provision of spaces of interaction and shared works 
- communication about different events

- a glossary of terms

- clear and structured documentation about the main possibilities. In the portal all the available requirements must be specified so it should follow a number of design rules that guaranty the easiness of use, the efficiency in the access and the main structure for navigation.

- the mechanisms for data warehousing must establish a group of security measures and confidentiality according to main Acts

- establish proper links from the main page to the other pages

- develop a logical structure of pages in folders with related contents.

In relation to the students, they must play a very active role in the process of learning, so some other tools are needed:

- a forum for people starting their subjects

- a forum with complementary activities, due to the variety of students

- a first solution service where the professor solves problems and other students can give their personal opinions

- a forum of study where doubts and critics can be solved

- $\quad$ self-evaluation exercises

- forums and distribution lists that help the students in their isolation by enabling them contact with other students and professors.

In order to facilitate the relation with other students and avoid isolation in this kind of distance university some other forums are established, such as contact forums and study forums. (See Figure 2)

In the same way, the contact with the professor-tutor in the Associate Centre and with the professor in the Central Part is established via the subject list of distribution, subject mail and study forum. Personal professor pages have also been developed for the professor-tutor to be closer to the personal and professional student profile

Due to the weight that the research activity has in the different areas, a series of forums have been de-

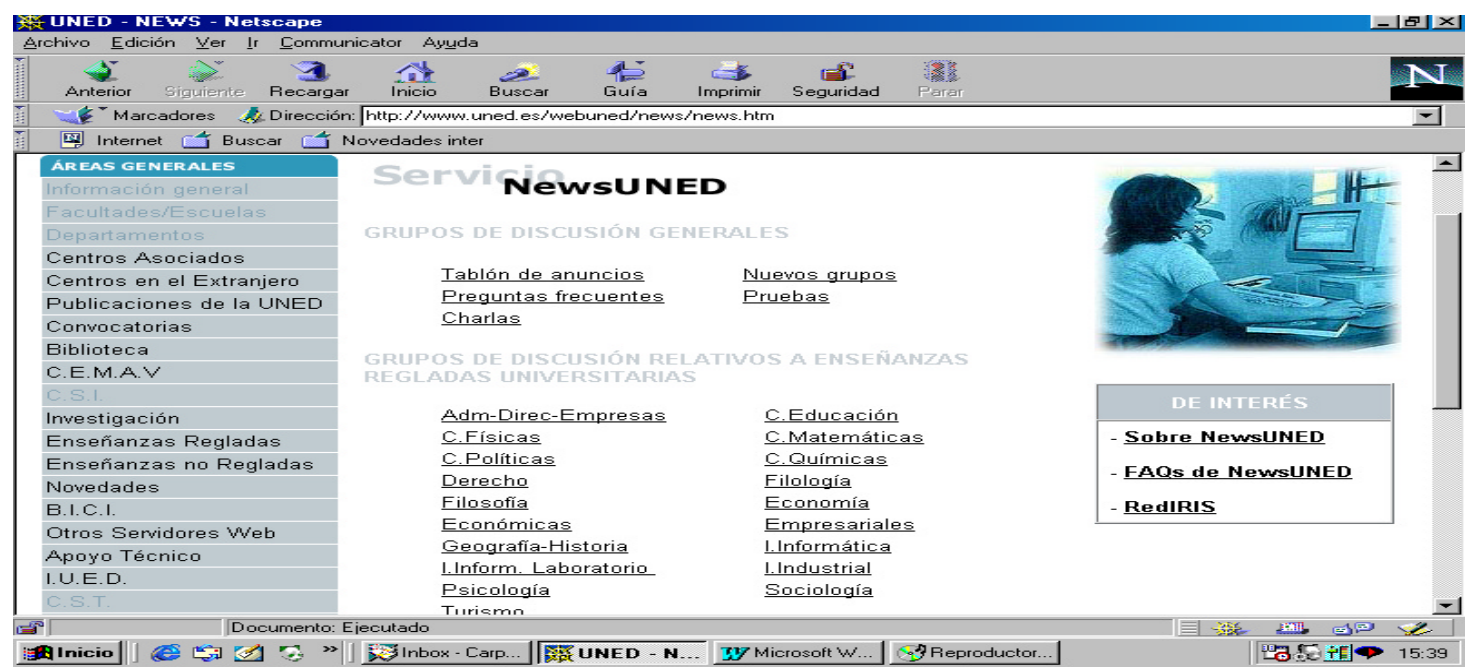

Figure 2. Main page of NewsUned 
veloped in order to promote the introduction of professors, tutors and interested students in projects:

- Pages of scientific diffusion

- Pages of collaboration

- Pages of research projects

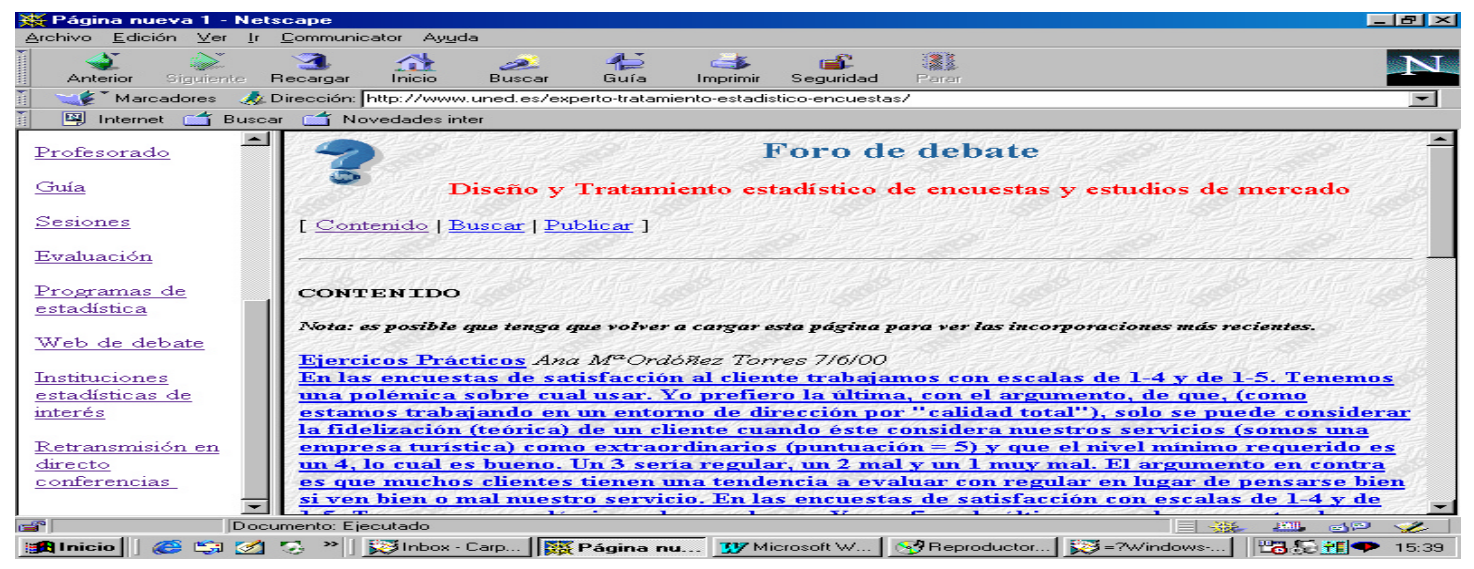

Figure 3. Research forums

There are research forums (Figure 3) so that the interested professor can know the main research areas in the area and take part in them.

In all the services mentioned above, a page with more frequent questions is included so the student can find there the solution to some common doubts. For the generation of answers and questions to these, some tools such as hyper-email are introduced.

Other services are included, such as self-evaluation exercises, exam questions, or distance evaluation tests.

For the development of the above mentioned aspects the UNED had the possibility of choosing some different technological solutions, such as Hot Potatoes, Perception Scientific Notebook, WebCT, LearningSpace, TopClass, ToolBook, CourseInf. In order to make a choice, the following criteria were considered:

Two related with system management,

1) cost-benefit analysis, 2) kind of support for the implementation,

Three related with the user

3) didactic criteria, 4) easiness of use, 5) flexibility in the tool

There are two main aims when developing a distance learning course: the first one is the organisation of the material in the server, and the second one is the use of all the resources that are offered for the completion of printed material.

\section{The WebCT}

Having taken into account the great quantity of available tools when designing an educational web, the UNED has chosen WebCT (Web Course Tools). It has been developed by the company Universal Learning Technology, and it comprises a number of very concrete functions and quite well defined objectives through a structured tree shape interface, a non complex one that allows use by non-experts. 


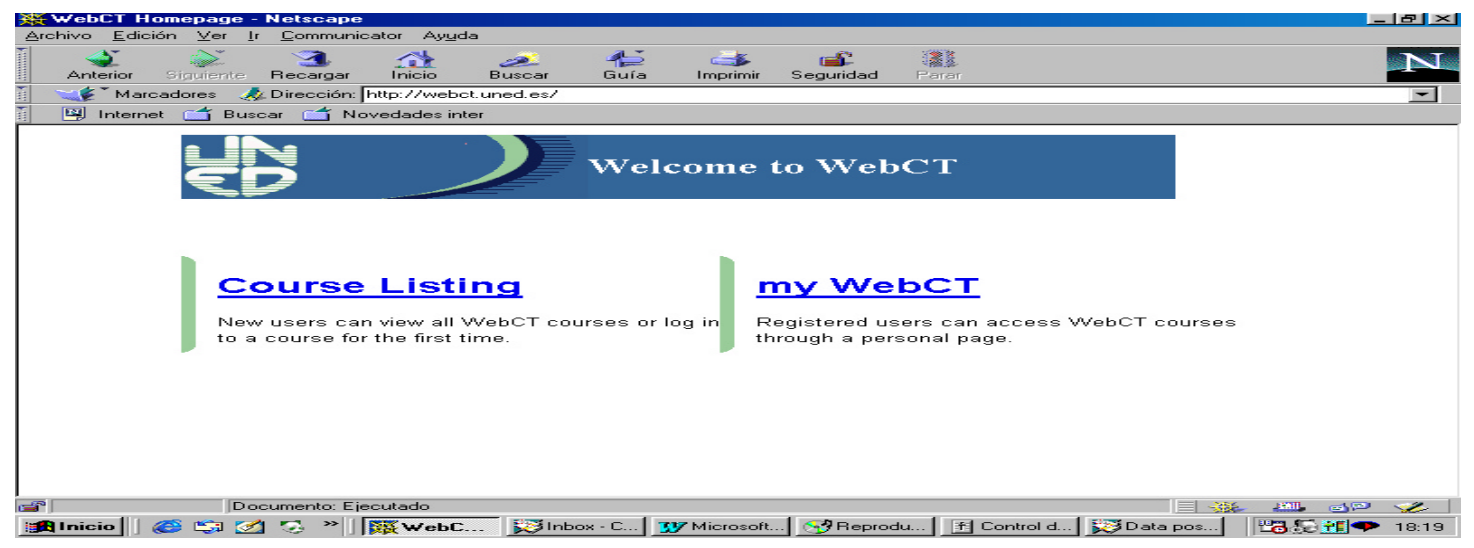

Figure 4. Main page of WebCT

WebCT (Figures 4 and 5) uses standard navigation technology for the access of students and the design tasks the professor needs to develop. It incorporates, a) email, a system of conferences, b) on line speech, c) management of courses, d) evaluation/exams, e) easiness in the configuration by using the interface (colours, page design); f) a group of educational tools to enable the learning (as for example, student presentation), the communication and collaboration; g) a series of administrative tools to help the teacher with the course distribution.

In general terms, WebCT includes the following data: a) multimedia possibilities, b) tools for student self-evaluation and "on line" evaluation; c) maintenance and marks distribution; d) it allows moderate discussions; e) electronic mail system; f) to supervise the course; g) active links via Internet; h) possibilities of real time chats; I) areas of student presentation and creation of pages of presentation; j) design tools and course management tools; k) security and access control by user identification and passwords; $\mathrm{K})$ the creation of security copies.

The structure of this tool is composed by a group of programs in the server (http://webct.uned.es) that receive demands of materials and services from outside the system, as a result of the interaction of professor and student with the system and, at the same time, to warehouse the material they must use to

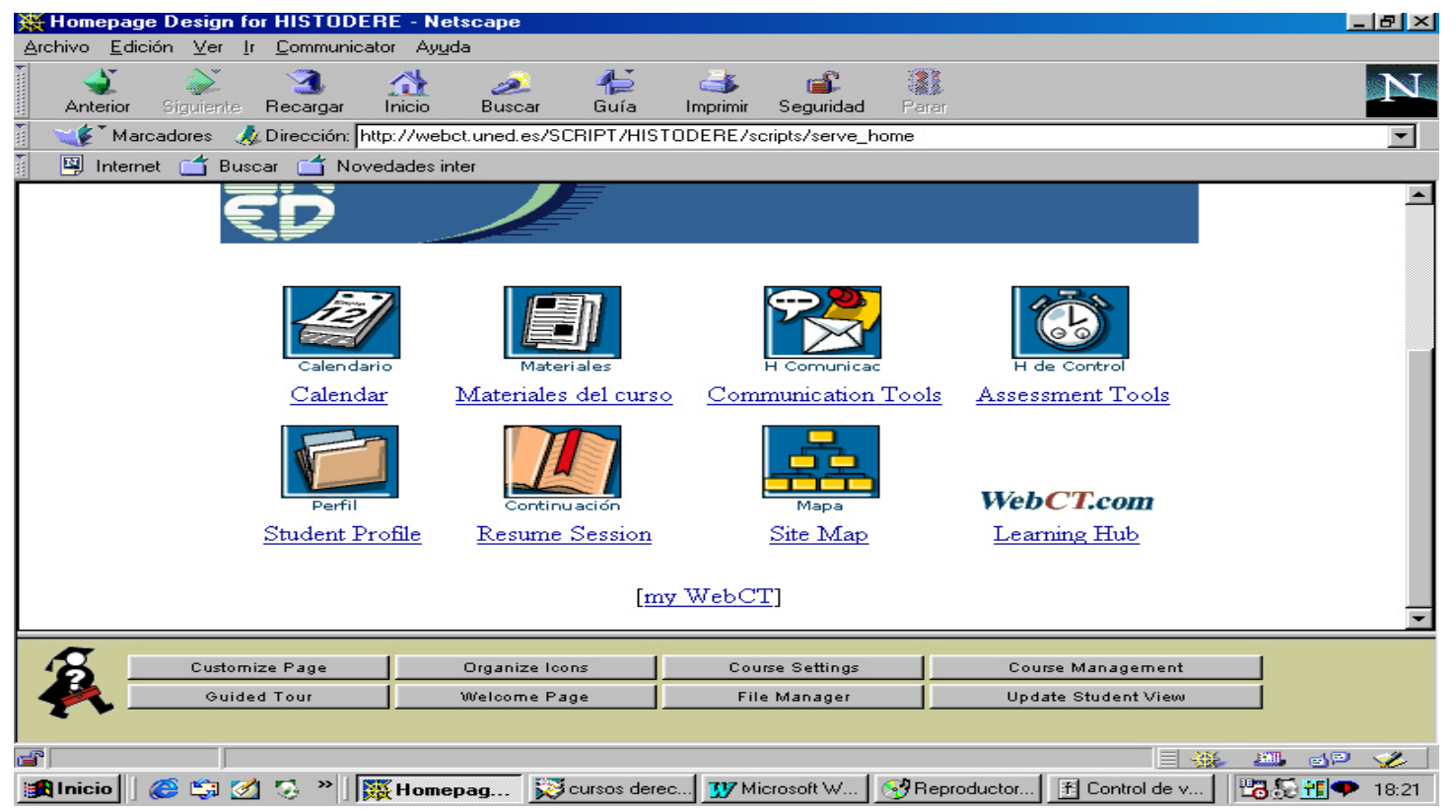

Figure 5. Main menu in WebCT 
answer the questions through their own files.

Using the conceptual bases of WebCT, we can show that the tutorial model uses elements of traditional teaching and supports the radial communication system; the professor teaches to a group of students in the same space and time. The main advantage of this system is that each student can follow his or her own learning path

It combines the existent resources in the university (such as exams, works, queries, etc.) with the ones typical in the tool (chats, forums, hypermedia materials, etc.) and at the same time, all the actualisation, organisation and evaluation are in professors' hands.

\section{Other Projects in Connection with Distance Tutorial and Subject Virtualiza- tion}

The UNED opened two years ago its own channel in Internet called TeleUNED

(http://www.teleuned.com). It is a multimedia platform that allows the direct transmission via web of important academic acts and the consultation with the appearance of "video on demand", of main materials such as video-cassettes and the production of its educational television space.

This has been completed with the inclusion of the radio programs in Internet, what it is called RadioUned (http://www.radiouned.com) that today includes 1600 hours of its own radio programs in the web.

TeleUned is now an element of special importance in the university. The demand of these services has increased and that it is the reason why today TeleUNED and the Video-conference via the integrated service digital network (ISDN) live together.

Up to now many students have been able to demand their marks via WAP technology through their mobile phones. (See Figure 6.) All the information about their subjects is situated in the portal CampusWAP.com (http://campuswap.com). The UNED, which has been the first University here in Spain in implementing this technology, has understood the great opportunities that it offers, and that it is the reason why it is going to make closer its WAP portal to the rest of universities.

The UNED has recently developed a service of phone access through Internet that is working right now



Figure 6. Student profile and WebCT 
(http://unedsat.uned.es). This service allows any UNED student to have a phone access to the professor at a very low cost, a local phone call. The great advantage of this service it is that the professor does not need to be trained in new technological requirements, since the communication is directly made from the student computer, via the UNED portal up to the professor's phone.

Another important service is the electronic book, which has become the first virtual university bookshop in Spanish language, Liberuned.com (http://www.liberuned.com). Each day we are more convinced about the advantages that the electronic book has in relation with the distribution and the associated price reduction.

\section{Conclusions}

New technological environments can promote a great number of efficiencies and potential benefits in distance learning. The establishment of these environments demands in people and processes new cognitive skills in which the different participants must be trained. The new paradigm of the introduction of multimedia tools, in general, and education and distance education, in particular, means for students and professors the development of new competencies and promotes consideration of communication in a different perspective from the traditional one. We have to consider that distance learning establishes a close relation between what and how to teach. Computers are a constant reference since all the course areas start and finish in the computers. Data and information are presented in multimedia formats, text, diskettes, videos and audiocassettes.

Nowadays technologies are more and more bi-directional and allow each time more of this kind of interaction between student and professor as well as amongst students. Communications via the Internet and electronic mail are two actual, clear examples of this interactive focus in the processes of distance learning. The application of these multimedia technologies to distance learning opens new alternatives for communication. They offer a more open and better distance learning. Students can have easier access through more flexible timetables and a better content quality. The main critical success factor is based in a proper pedagogical management of the developed processes with the decisive support of the most adequate technology.

\section{References}

Boticario, J.G. \& Gaudioso, E. (2000). Nuevos materiales didácticos y servicios telemáticos. Parte I. Unidad Técnica de Investigación y Formación de Recursos Tecnológicos, Madrid: IUED, UNED.

Cabanes, R. (1983). Experiencia y reflexiones sobre tecnología educativa en la empresa, Madrid: UNED.

García Aretio, L (coor.), (1996). La educación a distancia y la UNED. Estudios de Educación a Distancia, 21, 30 -42.

García Areito, L. (1997). El material impreso en la enseñanza a distancia, Madrid: UNED.

Hölmberg, B. (1982). Recent research into education, Feruniversität: Hagen.

Información General 2002/2003 UNED, Madrid.

Keegan, D.J. (1980). On the nature of distance education, Feruniversität: Hagen.

Ramos, E. (1995). La metodología, los medios y la tecnología en la enseñanza a distancia, A Distancia, 1, 80-87. 


\section{Biographies}

Dr de Pablos is an Associate Professor at the Rey Juan Carlos University Madrid. She lectures the Managing of Information Systems and has published about the effect of information technologies in educ ation and the effect of IT over organisational performance.

Dr López is a lecturer at the UNED University. She lectures Economy and Production and has a long experience in lecturing in a distance learning education basis. She studies the impacts of distance learning in the Organisational results. 